\title{
1 Diverging seasonal extremes for ocean acidification during the twenty-first century
}

4

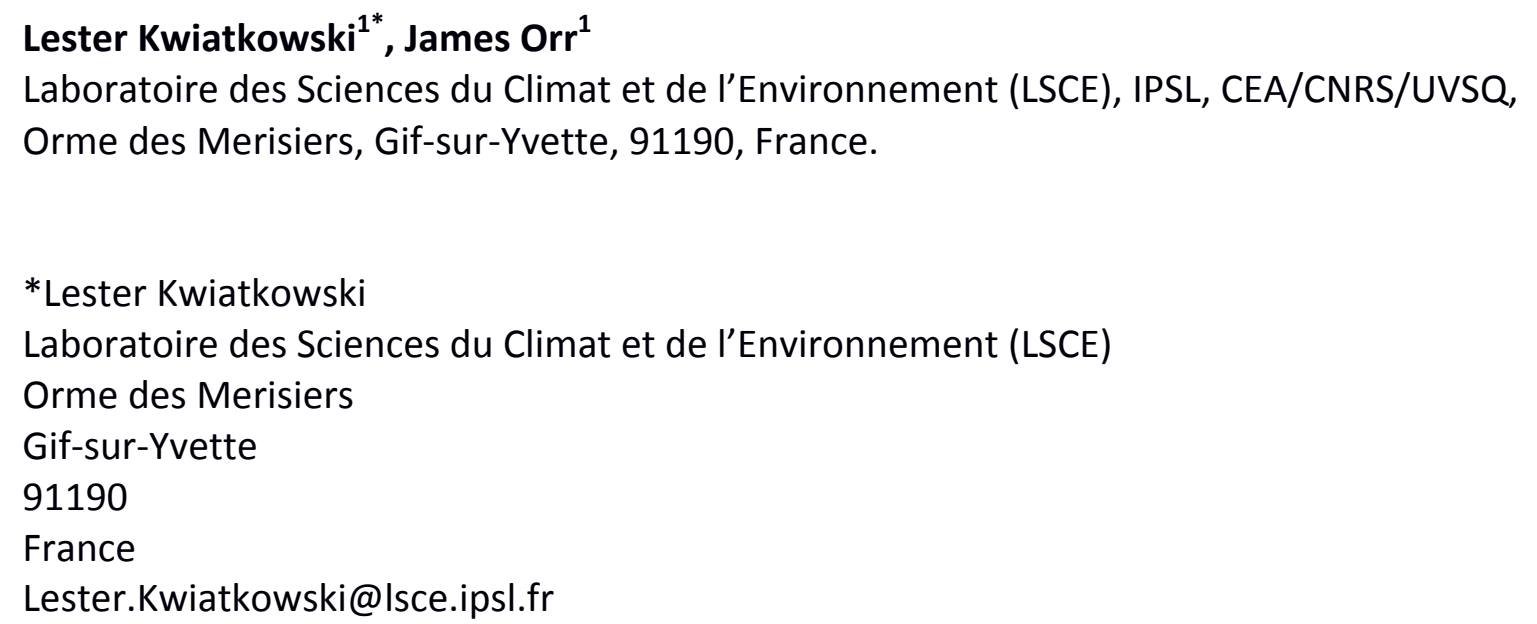

How ocean acidification will affect marine organisms depends on changes in both the longterm mean and the short-term temporal variability of carbonate chemistry ${ }^{1,2,3,4,5,6,7,8}$. While the decadal-to-centennial response to atmospheric $\mathrm{CO}_{2}$ and climate change is constrained by observations and models ${ }^{1,9}$, little is known about corresponding changes in seasonality $^{10,11,12}$, particularly for $\mathrm{pH}$. Here we assess the latter by analysing 9 Earth System Models (ESMs) forced with a business-as-usual emissions scenario ${ }^{13}$. During the twentyfirst century, the seasonal cycle of surface-ocean pH was attenuated by $16 \pm 7 \%$, on average, while that for hydrogen ion concentration $\left[\mathrm{H}^{+}\right]$was amplified by $81 \pm 16 \%$. Simultaneously, the seasonal amplitude of aragonite saturation state $\left(\Omega_{\text {arag }}\right)$ was attenuated except in the subtropics where it was amplified. These contrasting changes derive from regionally varying sensitivities of these variables to atmospheric $\mathrm{CO}_{2}$ and climate change and diverging trends in seasonal extremes in the primary controlling variables (temperature, dissolved inorganic carbon, and alkalinity). Projected seasonality changes will tend to exacerbate impacts of increasing $\left[\mathrm{H}^{+}\right]$on marine organisms during summer and ameliorate impacts during winter, although the opposite holds in the high latitudes. Similarly over most of the ocean, impacts from declining $\Omega_{\text {arag }}$ are likely to be intensified during summer and dampened during winter. 
Ocean $\mathrm{CO}_{2}$ uptake affects marine chemistry via ocean acidification ${ }^{1,9,14}$, a process that increases concentrations of $\mathrm{CO}_{2}, \mathrm{H}^{+}$and $\mathrm{HCO}_{3}{ }^{-}$, and reduces levels of $\mathrm{pH}$ and $\mathrm{CO}_{3}{ }^{2-}$. Although much effort has been devoted to assessing the direct and indirect effects of increasing atmospheric $\mathrm{CO}_{2}$ on the mean state of these ocean carbonate chemistry variables, few studies have addressed the corresponding changes in their seasonal cycles ${ }^{10,11,12}$.

The seasonal cycles of ocean carbonate chemistry variables are the result of variations in the seasonality of different physical and biological processes ${ }^{6,7}$. Those for $p \mathrm{CO}_{2}$ and $\mathrm{pH}$ are largely regulated by variations in temperature in the subtropics, while at higher latitudes their oscillations are typically dominated by biological uptake and release of $\mathrm{CO}_{2}$ (photosynthesis and respiration). In contrast, temperature plays a minor role in controlling the seasonal cycles of the carbonate saturation state of seawater $\left(\Omega=\left[\mathrm{Ca}^{2+}\right]\left[\mathrm{CO}_{3}^{2-}\right] / K_{s p}\right)$ even at lower latitudes; rather, it is the variability of total alkalinity and dissolved inorganic carbon that dominates, ${ }^{6,7}$.

To survive, marine organisms must cope with variations in their local environment, however many may be highly sensitive to changes in ocean carbonate chemistry ${ }^{15,16}$. Calcifying species such as echinoderms, byrozoans and cnidarians exhibit depressed calcification, growth and survival rates at lower $\Omega_{\text {arag/calc }}\left(\right.$ refs. ${ }^{3,4,15}$ ). In teleost fish and marine invertebrates, ion exchange is reduced by extracellular acidosis or high external $\left[\mathrm{H}^{+}\right]$, depressing protein synthesis and metabolic rates ${ }^{17}$. Physiological and behavioural functioning is also sensitive to $p \mathrm{CO}_{2}$, with high external concentrations impairing olfactory discrimination ${ }^{18}$ and predator-prey responses ${ }^{19}$.

Accounting for seasonal variability in carbonate chemistry influences the timing of the projected onset of $\mathrm{CaCO}_{3}$ undersaturation ${ }^{10,11,20}$, when waters become corrosive to pure aragonite $\left(\Omega_{\text {arag }}<1\right)$ and calcite $\left(\Omega_{\text {calc }}<1\right)$ (i.e., metastable and stable forms of $\left.\mathrm{CaCO}_{3}\right)$. These seasonal variations also affect when surface waters will reach a proposed threshold, beyond which $p \mathrm{CO}_{2}$ levels may become damaging ${ }^{12}$. Here we explore how seasonality of surfaceocean $\left[\mathrm{H}^{+}\right], \mathrm{pH}$ and $\Omega_{\text {arag }}$ will respond to projected increases of atmospheric $\mathrm{CO}_{2}$ and climate change during the twenty-first century. Unlike studies that have assumed unchanging seasonality, combining observational estimates of present seasonality (repeated in time) with model projections of the change in mean state ${ }^{10,11}$, we use an ensemble of 9 Earth System Models (ESMs) containing coupled ocean biogeochemistry schemes. Thus we assess how seasonality is affected by increasing concentrations of atmospheric $\mathrm{CO}_{2}$ and climatechange driven changes in sea surface temperature and biology ${ }^{9,21}$.

Ocean biogeochemistry models (OBM) generally reproduce the amplitude and phase of observational estimates for seasonal air-sea $\mathrm{CO}_{2}$ fluxes in the Pacific ${ }^{22}$, Atlantic ${ }^{23}$ and Indian Oceans ${ }^{24}$ while their skill in high latitude regions is more limited ${ }^{23,25,26}$. We found consistent results for the CMIP5 ESMs that include an OBM. The models broadly capture the zonalmean patterns of seasonal changes in $\left[\mathrm{H}^{+}\right]\left(\mathrm{r}^{\sim} 0.8\right)$ and $\Omega_{\text {arag }}(\mathrm{r} \sim 0.95)$ of observational climatologies (Supplementary Figs. 1-6). Hence they appear to offer the best option to assess projected changes in seasonality during the coming century. Nonetheless, model performance in the Southern Ocean is particularly limited, with certain models negatively correlated with the $\left[\mathrm{H}^{+}\right]$climatology, possibly due to excessive simulated warming in 
summer ${ }^{25}$ or underestimated winter convective $\mathrm{CO}_{2}$ entrainment and the impact of biological $\mathrm{CO}_{2}$ uptake ${ }^{26}$.

Projected trends in seasonality were evaluated for the business-as-usual (2006-2100) Representative Concentration Pathway 8.5 (RCP8.5) ${ }^{13}$ relative to results from the historical simulation ${ }^{27}$ (1990-1999). Changes in seasonality were determined by subtracting a cubic spline fit from the monthly time series in each grid cell and calculating the annual peak-topeak amplitude for each year of the detrended dataset. Both the mean state and seasonality of projected $\left[\mathrm{H}^{+}\right], \mathrm{pH}$ and $\Omega_{\text {arag }}$ change over the twenty-first century, as illustrated in Figure 1 for one model.

During this century, the amplitude of seasonal cycle in $\left[\mathrm{H}^{+}\right]$is projected to increase by $81 \pm 16$ $\%$ (multi-model mean \pm 1 SD) (Fig. 2a). Increases in seasonal amplitudes of $\left[\mathrm{H}^{+}\right]$are generally higher in the high latitudes, particularly in the Arctic where the average amplification is $147 \pm 57 \%$ (Fig. 3a, S8). Yet unlike the seasonal amplitude for $\left[\mathrm{H}^{+}\right]$, that for $\mathrm{pH}$ is projected to decline globally, on average by $16 \pm 7 \%$ during the twenty-first century (Fig. $2 b$ ). Attenuation is generally more intense in the low and mid-latitudes but also occurs over most of the highlatitude ocean (Fig. 3b, S8). Given that $\mathrm{pH}$ is directly related to $\left[\mathrm{H}^{+}\right]$, it is counterintuitive that while the seasonal amplitude in $\left[\mathrm{H}^{+}\right]$increases, the seasonal amplitude in $\mathrm{pH}$ declines. However, the log transformation implies that

$$
d p H=\frac{-1}{2.303} \frac{d\left[H^{+}\right]}{\left[H^{+}\right]}
$$

112 That is, the seasonal amplitude of $\mathrm{pH}$ depends not only on the seasonal amplitude of $\left[\mathrm{H}^{+}\right]$but also on the annual mean $\left[\mathrm{H}^{+}\right]$. For the seasonal amplitude in $\mathrm{pH}$ to remain constant in time, the relative change in the seasonal amplitude of $\left[\mathrm{H}^{+}\right]$would have to equal the relative change in annual mean $\left[\mathrm{H}^{+}\right]$. Although the CMIP5 models project that the global mean, seasonal amplitude of $\left[\mathrm{H}^{+}\right]$increases by $81 \pm 16 \%$ over the twenty-first century, the annual global mean $\left[\mathrm{H}^{+}\right]$simultaneously increases by $117 \pm 3 \%$. Hence their combination results in reduced seasonal amplitude of $\mathrm{pH}$. In contrast, in the parts of the Arctic and Southern Ocean that exhibit increases in the seasonal amplitude of $\mathrm{pH}$, the relative change in the seasonal amplitude of $\left[\mathrm{H}^{+}\right]$is larger than the relative change in the $\left[\mathrm{H}^{+}\right]$mean state. Yet in those regions, there is less agreement among models about the sign of these changes (Figs. 3b, 122 S8).

123
Regarding $\Omega_{\text {arag, }}$ its global average seasonal amplitude is attenuated by $9 \pm 8 \%$ during the twenty-first century (Fig. 3c). Attenuation can exceed $40 \%$ in the temperate-to-polar zones, while in the subtropics, where the amplitude of the seasonal cycle of $\Omega_{\text {arag }}$ is much smaller (Supplementary Fig. 7), there is amplification of up to $30 \%$ (Fig. 3c), as discussed below. These projected changes in the seasonal amplitude of $\left[\mathrm{H}^{+}\right], \mathrm{pH}$ and $\Omega_{\text {arag }}$ result from nonidentical changes in both the seasonal maxima and minima (Fig. 1, S12).

To further investigate the causes of changes in seasonal amplitudes of derived variables $\left[\mathrm{H}^{+}\right]$ and $\Omega_{\text {arag, }}$ we used 2 complementary approaches: (1) idealised simulations and (2) first-order Taylor-series deconvolution. The idealised simulations partition the geochemical versus radiative effects of increasing atmospheric $\mathrm{CO}_{2}$, where the geochemical effect is due to 
ocean carbon uptake and the radiative effect influences carbonate chemistry through rising temperatures and simultaneous changes in marine biological activity. The deconvolution quantifies how the seasonal amplitude of each derived variable $(\Delta y)$, is affected by changes in temperature $(T)$, salinity $(\mathrm{S})$, dissolved inorganic carbon $\left(C_{T}\right)$ and total alkalinity $\left(A_{T}\right)$, i.e., four model variables used to calculate carbonate chemistry. That is for $y=f\left(C_{T}, A_{T}, T, S\right)$,

$$
\Delta y=\left(\frac{\partial y}{\partial C_{T}}\right) \Delta C_{T}+\left(\frac{\partial y}{\partial A_{T}}\right) \Delta A_{T}+\left(\frac{\partial y}{\partial T}\right) \Delta T+\left(\frac{\partial y}{\partial S}\right) \Delta S
$$

142

143

144

145

146

147

148

149

150

151

152

153

154

155

156

157

158

159

160

161

162

163

164

165

166

167

168

169

170

171

172

173

174

175

176

177

178

179

where the partial differentials are estimated numerically and $\Delta T, \Delta C_{T}, \Delta A_{T}$ and $\Delta S$ are the changes in input variables, synchronous with $\Delta y$, assuming other contributions are negligible. For the change in amplitude, Equation (2) is evaluated separately with decadal mean seasonal cycles for the first and last simulated decades of the RCP8.5 scenario, and then the latter is subtracted from the former.

This deconvolution illustrates how the proximate drivers of seasonal amplification of $\left[\mathrm{H}^{+}\right]$ vary spatially. In the mid-to-high latitudes it is the residual effect of opposing increases in the terms for dissolved inorganic carbon $\left(\left(\partial \mathrm{H}^{+} / \partial C_{T}\right) \Delta C_{T}\right)$ and total alkalinity $\left(\left(\partial \mathrm{H}^{+} / \partial A_{T}\right) \Delta A_{T}\right)$ that dominates. However, in the low latitudes, changes in these two terms largely compensate, so it is the increase in the temperature term $\left(\left(\partial \mathrm{H}^{+} / \partial \mathrm{T}\right) \Delta \mathrm{T}\right)$ that dominates (Supplementary Fig. 9). Because the sensitivities of $\mathrm{H}^{+}$to $C_{T}$ and $A_{T}$ (partial differentials) are roughly equal and opposite, it is the balance between $\Delta C_{T}$ and $\Delta A_{T}$ that control the change in seasonal amplitude of $\left[\mathrm{H}^{+}\right]$in the mid-to high latitudes (Supplementary Fig. 10). One cannot assume that $\Delta A_{T}$ remains constant while only $\Delta C_{T}$ will change. For instance, changes in $\Delta A_{T}$ will be decoupled from those of $\Delta C_{T}$ due to an altered hydrological cycle. Increased freshwater input dilutes $C_{T}$ and $A_{T}$, but $C_{T}$ then tends to equilibrate with atmospheric $\mathrm{CO}_{2}$, unlike $A_{\mathrm{T}}$. Hence addition of low alkalinity freshwater reduces $\mathrm{pH}$, despite the opposite tendency from dilution alone. The high latitudes will experience this effect most, from enhanced precipitation, ice melt, and river runoff. Decoupling will also result from anthropogenic $\mathrm{CO}_{2}$ invasion and changes in primary production. In the low latitudes, while the $C_{\mathrm{T}}$ and $A_{\mathrm{T}}$ terms are small and compensating, the temperature term dominates, enhanced by a doubling of $\partial \mathrm{H}^{+} / \partial \mathrm{T}$ (Supplementary Fig. 11). The ultimate drivers of this seasonal amplification in $\left[\mathrm{H}^{+}\right]$are demonstrated by the idealised simulations, which show that it is the geochemical effect of increasing atmospheric $\mathrm{CO}_{2}$ and consequently reduced buffer capacity ${ }^{29,30}$ that is responsible for $92 \%$ of global amplification, while the radiative effect provides minor reinforcement (Fig. 4, S13).

For $\Omega_{\text {arag, }}$, the proximate drivers of the general attenuation of its seasonal amplitude are a decline in the $C_{T}$ term $\left(\left(\partial \Omega_{\text {arag }} / \partial C_{T}\right) \Delta C_{T}\right)$ which typically outweighs an opposing increase in the $A_{T}$ term $\left(\left(\partial \Omega_{\text {arag }} / \partial A_{T}\right) \Delta A_{T}\right)$ (Supplementary Figs. 9-10). In the subtropics though, there is little change in the $A_{T}$ term, while the $C_{T}$ term increases due to a larger change in $\Delta C_{T}$, driving amplification of the $\Omega_{\text {arag seasonal cycle in these regions. The ultimate driver of the seasonal }}$ attenuation in $\Omega_{\text {arag }}$ is the geochemical effect of increasing atmospheric $\mathrm{CO}_{2}$ which is responsible for $>100 \%$ of global attenuation, being partly offset by the radiative effect (Fig. 4 , S13). In contrast, the subtropical amplification of the seasonal cycle of $\Omega_{\text {arag }}$ results from the radiative effect driving enhanced amplification over the low latitudes in combination with the weaker attenuation from the geochemical effect in the subtropics. 
We have shown that under a business-as-usual emissions scenario, the seasonal variability of ocean carbonate chemistry is projected to change substantially during this century. Despite the diversity of OBMs in the multi-model ensemble ${ }^{9,21}$, spatial patterns of the change in seasonal amplitude of $\left[\mathrm{H}^{+}\right], \mathrm{pH}$, and $\Omega_{\text {arag }}$ are generally consistent (Fig. 3, S8). Previously it was shown that increasing atmospheric $\mathrm{CO}_{2}$ will amplify the seasonal cycle of surface-ocean $p \mathrm{CO}_{2}$ (ref. ${ }^{12}$ ), potentially resulting in earlier exposure to detrimental $p \mathrm{CO}_{2}$ conditions for marine organisms. Here we show that increasing atmospheric $\mathrm{CO}_{2}$ must also amplify the seasonal cycle of $\left[\mathrm{H}^{+}\right]$in a similar manner. This is consistent with the near-linear relationship between $\left[\mathrm{H}^{+}\right]$and $p \mathrm{CO}_{2}$ for annual-mean trends during the twenty-first century ${ }^{31}$.

Amplified $\left[\mathrm{H}^{+}\right]$seasonality may worsen impacts from the long-term mean increase in $\left[\mathrm{H}^{+}\right]$, potentially resulting in earlier seasonal exposure to conditions that cause physiological acidosis and depress protein synthesis and metabolic rates in marine organisms. In the low latitudes, this enhanced exposure is most likely to occur during summer when warming drives the $\left[\mathrm{H}^{+}\right]$seasonal high. In the high latitudes, enhanced exposure is most likely to occur when the effect of photosynthesis on $\left[\mathrm{H}^{+}\right]$drawdown is limited ${ }^{6,7}$. But amplified $\left[\mathrm{H}^{+}\right]$ seasonality will also diminish exposure to conditions that cause acidosis during seasonal lows, e.g., in winter months in the low-latitudes and during phytoplankton blooms in the high-latitudes.

The seasonal amplitude of $\Omega_{\text {arag }}$ is projected to amplify in some regions and attenuate in others. Attenuation dominates throughout most of the ocean owing to increases in aqueous carbon dioxide $\left[\mathrm{CO}_{2}{ }^{*}\right]$, which reduces carbonate ion $\left[\mathrm{CO}_{3}{ }^{2-}\right]$ and hence the buffer capacity. In the subtropics though, the seasonal amplitude of $\Omega_{\text {arag }}$ increases because amplification driven by the radiative effect of $\mathrm{CO}_{2}$ dominates the locally weak geochemical effect. The general attenuation of the seasonal amplitude of $\Omega_{\text {arag }}$ is likely to exacerbate the impact of declining $\Omega_{\text {arag }}$ during the summer high while dampening the impact of declining $\Omega_{\text {arag }}$ during the winter low.

The same processes that will affect future seasonal variability, particularly the direct geochemical effect from the atmospheric $\mathrm{CO}_{2}$ increase and the corresponding indirect effect from radiative warming, are likely to affect future diurnal variability. Indeed we estimate an amplification of the diurnal cycle of $\left[\mathrm{H}^{+}\right](122 \%)$ and an attenuation of the diurnal cycle of $\Omega_{\text {arag }}(20 \%)$ that are similar to our estimates for the seasonal cycle, based on differences in observations of diel $\mathrm{pH}$ variability reported for two adjacent sites in the Bay of Naples, a control station and a station where natural venting of pure $\mathrm{CO}_{2}$ has perturbed oceanic $p \mathrm{CO}_{2}$ to reach levels expected for the late twenty-first century (Table S2; ref. ${ }^{32}$ ). Future research should assess how altered carbonate chemistry variability on both diurnal ${ }^{33,34}$ and seasonal timescales will affect marine organisms, especially those suspected to be vulnerable to ocean acidification.

The diversity in projected changes in seasonal extremes of $\left[\mathrm{H}^{+}\right], \mathrm{pH}, \Omega_{\text {arag }}$ and $p \mathrm{CO}_{2}$ emphasizes the need to improve our understanding of the mechanisms that control how specific marine organisms are affected by ocean acidification. In particular, we will need to study the sensitivity of marine organisms to these simultaneous yet contrasting changes in seasonality to be able to assess aggregate effects on marine communities. 
a

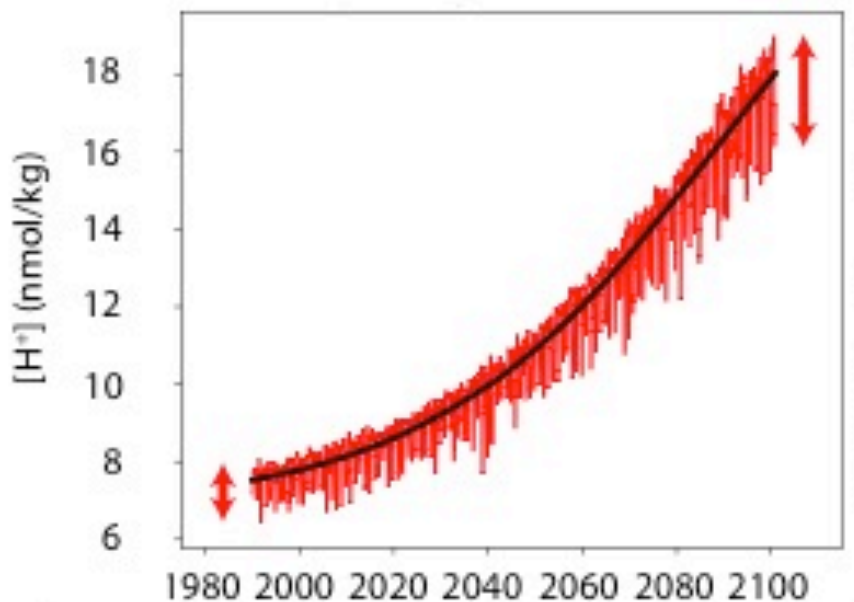

d



1980200020202040206020802100



b
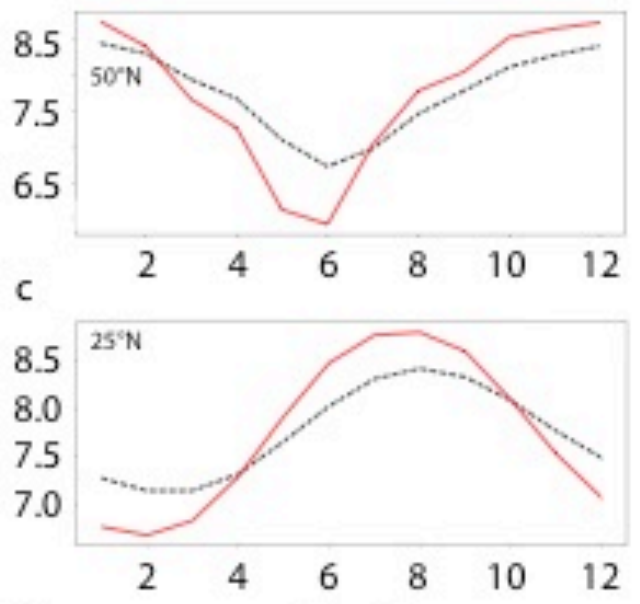

e Month

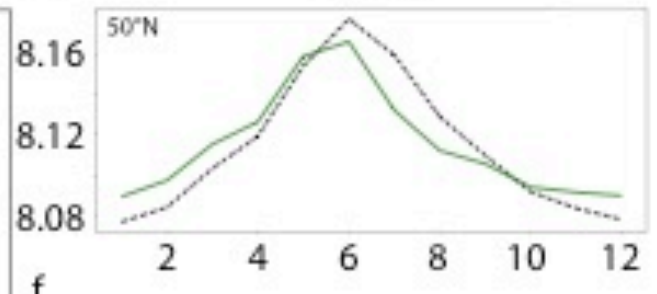

f

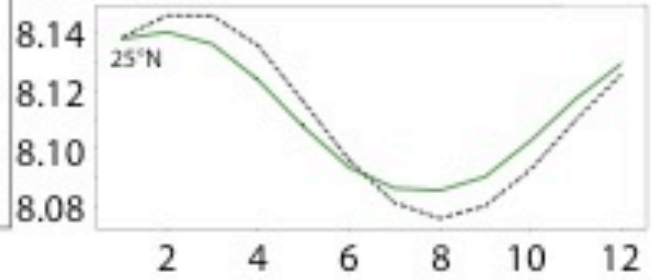

h Month


i

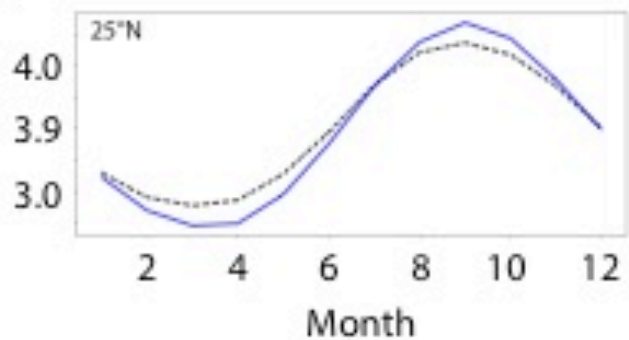

Figure 1. Changing seasonal cycles of carbonate chemistry variables. The projected a-c, $\left[\mathrm{H}^{+}\right]$ d-f, pH and g-i, $\Omega_{\text {arag }}$ under the historical and RCP8.5 scenario of one CMIP5 model (MPIESM-LR). First column, monthly values and the long-term mean trend from an illustrative grid cell in the South Pacific $\left(110^{\circ} \mathrm{W}, 40^{\circ} \mathrm{S}\right)$. Second column, the detrended zonal-mean seasonal cycles in the periods $1990-1999$ (dashed) and $2090-2099$ (line) at $25^{\circ} \mathrm{N}$ and $50^{\circ} \mathrm{N}$. 
a

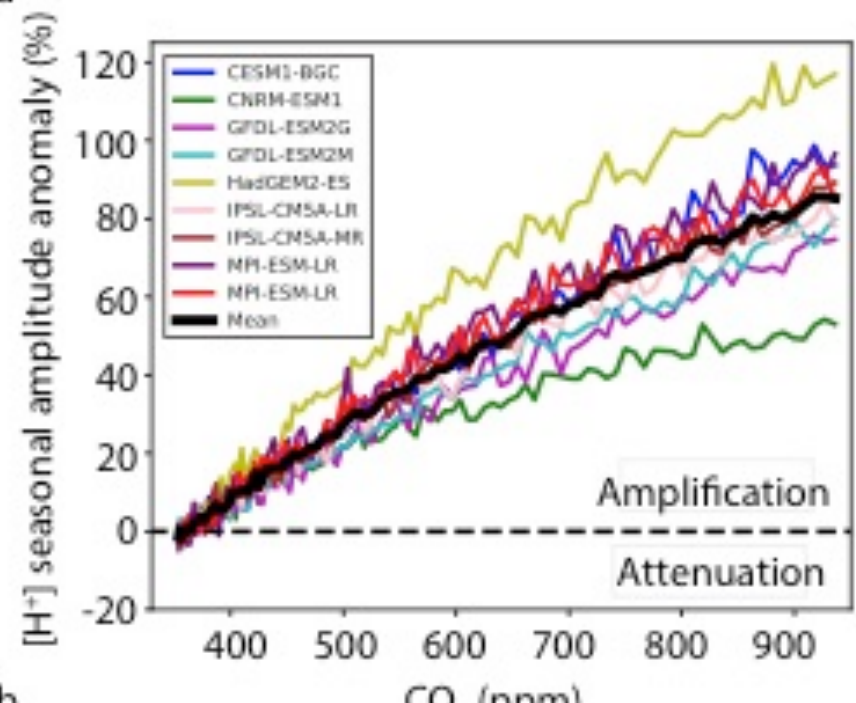

b

$\mathrm{CO}_{2}$ (ppm)
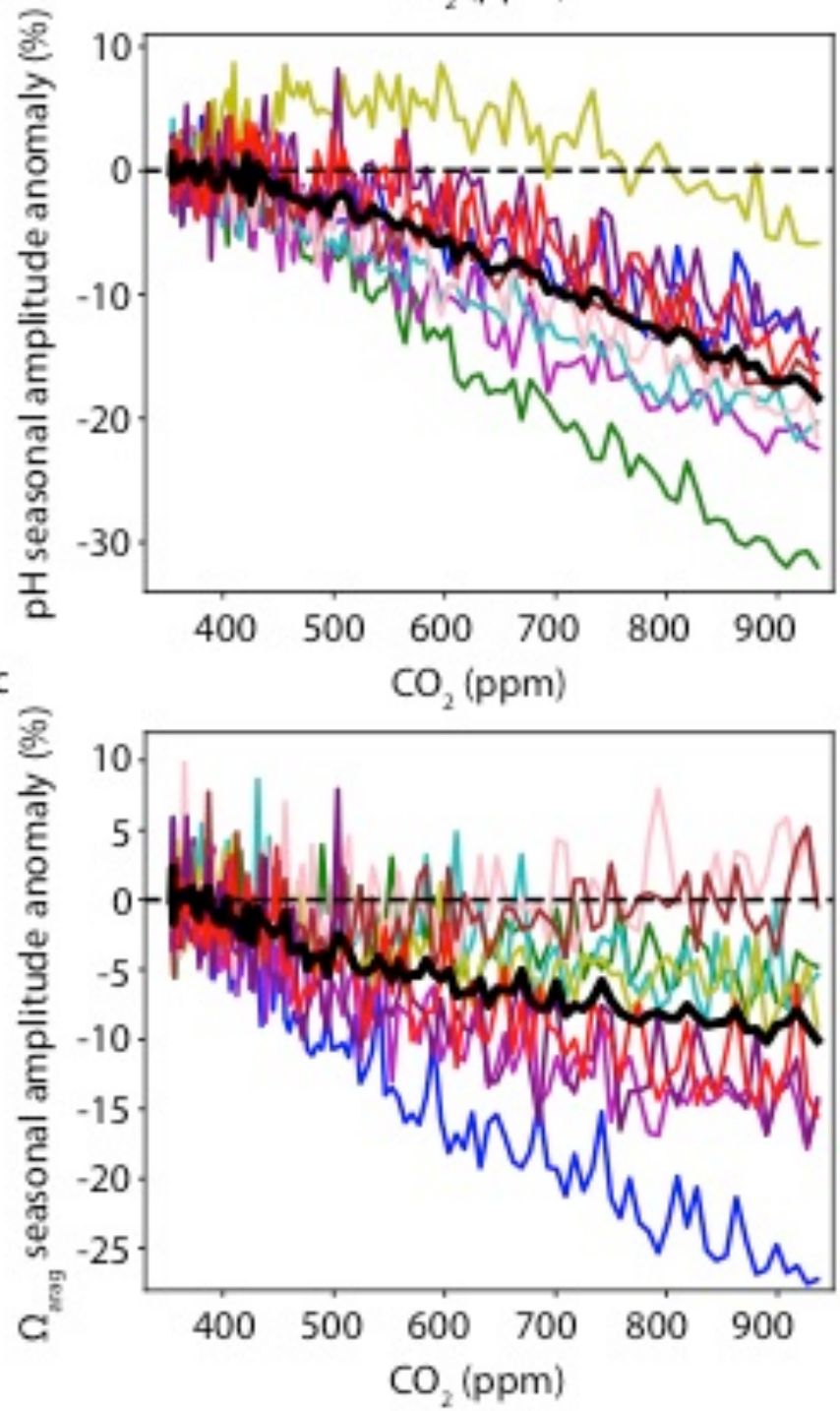

Figure 2. Relative change in the seasonal amplitude of carbonate chemistry variables with rising atmospheric $\mathrm{CO}_{2}$. Global anomaly in the seasonal amplitudes of $\mathbf{a},\left[\mathrm{H}^{+}\right] \mathbf{b}, \mathrm{pH}$ and $\mathbf{c}$, $\Omega_{\text {arag }}$ relative to mean 1990 s values as a function of atmospheric $\mathrm{CO}_{2}$. 
$21^{\text {st }}$ century change in seasonal amplitude (\%)



Figure 3. The twenty-first century changes in seasonal amplitudes. The model mean anomaly in the seasonal amplitude of $\mathbf{a},\left[\mathrm{H}^{+}\right] \mathbf{b}, \mathrm{pH}$ and $\mathbf{c}, \Omega_{\text {arag }}$ in the 2090s relative to the 1990s. Stippling shows areas of high confidence as determined by model sign agreement with a standard of 8 out of 9 models representing significance. 

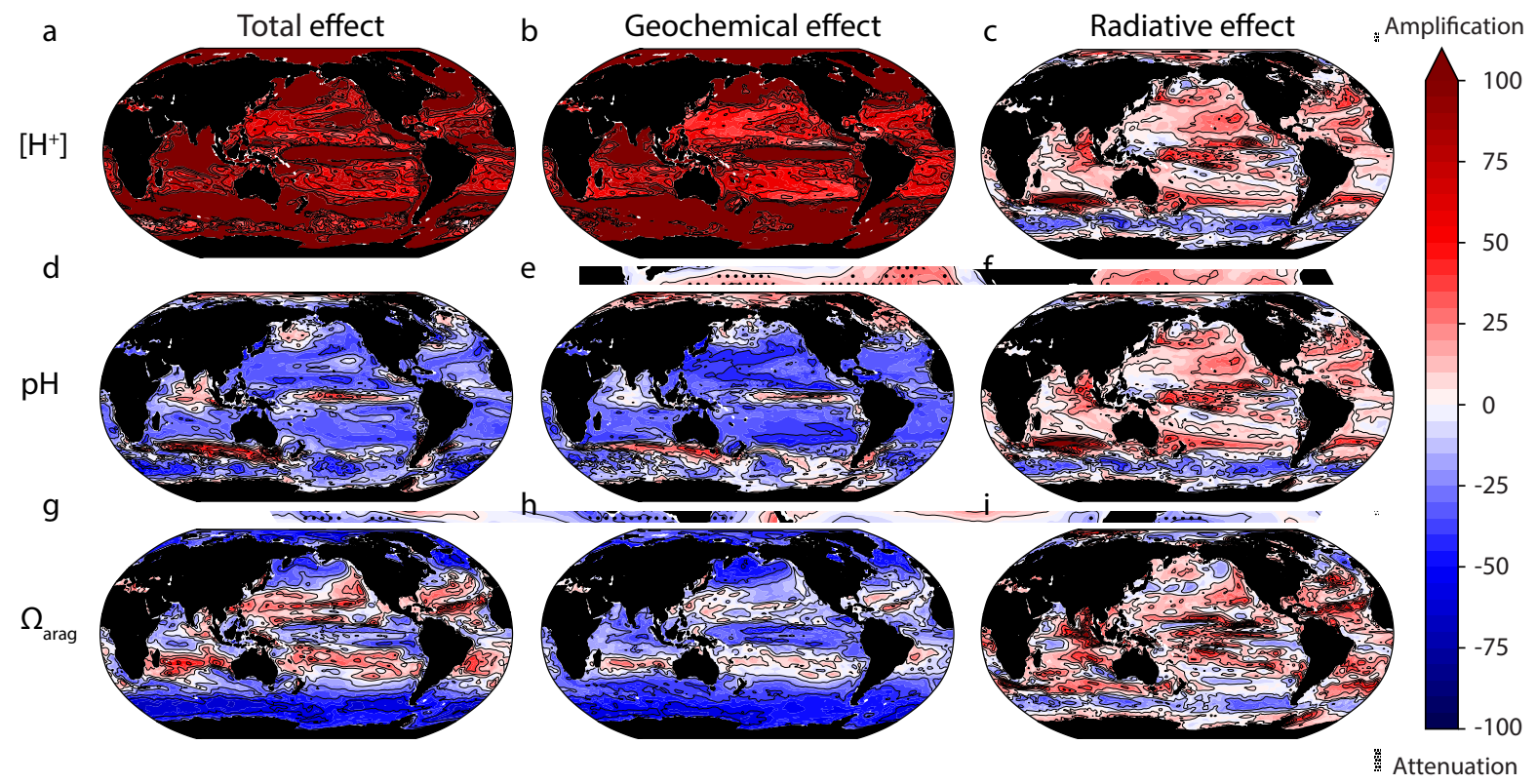

Figure 4. Partitioning of geochemical and radiative effects of atmospheric $\mathrm{CO}_{2}$ on seasonality change. The model mean anomaly $(\%)$ in the seasonal amplitudes of a-c, $\left[\mathrm{H}^{+}\right], \mathbf{d}-$ f, $\mathrm{pH}$ and $\mathbf{g - i}, \Omega_{\text {arag }}$ due to the geochemical, radiative and combined effect of atmospheric $\mathrm{CO}_{2}$. Anomalies are calculated for the last decade of $4 \times \mathrm{CO} 2$ simulations relative to the first decade. 
1. Orr, J. C. et al. Anthropogenic ocean acidification over the twenty-first century and its impact on calcifying organisms. Nature 437, 681-686 (2005).

2952 2. Wootton, J. T., Pfister, C. A. \& Forester, J. D. Dynamic patterns and ecological impacts 296 of declining ocean pH in a high-resolution multi-year dataset. Proc. Natl. Acad. Sci. 105, 297 18848-18853 (2008).

298 3. Albright, R. et al. Reversal of ocean acidification enhances net coral reef calcification. 299 Nature 531, 362-365 (2016).

300 4. Kwiatkowski, L. et al. Nighttime dissolution in a temperate coastal ocean ecosystem 301 increases under acidification. Sci. Rep. 6, 22984 (2016).

$302 \quad 5 . \quad$ Shaw, E. C., McNeil, B. I., Tilbrook, B., Matear, R. \& Bates, M. L. Anthropogenic 303 changes to seawater buffer capacity combined with natural reef metabolism induce extreme 304 future coral reef CO2 conditions. Glob. Change Biol. 19, 1632-1641 (2013).

305 6. Takahashi, T. et al. Climatological distributions of $\mathrm{pH}, \mathrm{pCO} 2$, total CO2, alkalinity, and $306 \mathrm{CaCO} 3$ saturation in the global surface ocean, and temporal changes at selected locations. 307 Mar. Chem. 164, 95-125 (2014).

308 7. Hagens, M. \& Middelburg, J. J. Attributing seasonal pH variability in surface ocean 309 waters to governing factors. Geophys. Res. Lett. 43, 2016 GL071719 (2016).

310 8. Takeshita, Y. et al. Including high-frequency variability in coastal ocean acidification 311 projections. Biogeosciences 12, 5853-5870 (2015).

312 9. Bopp, L. et al. Multiple stressors of ocean ecosystems in the 21st century: projections 313 with CMIP5 models. Biogeosciences 10, 6225-6245 (2013).

314 10. McNeil, B. I. \& Matear, R. J. Southern Ocean acidification: A tipping point at 450-ppm 315 atmospheric CO2. Proc. Natl. Acad. Sci. 105, 18860-18864 (2008).

316 11. Sasse, T. P., McNeil, B. I., Matear, R. J. \& Lenton, A. Quantifying the influence of CO2 317 seasonality on future aragonite undersaturation onset. Biogeosciences 12, 6017-6031 318 (2015).

319 12. McNeil, B. I. \& Sasse, T. P. Future ocean hypercapnia driven by anthropogenic 320 amplification of the natural CO2 cycle. Nature 529, 383-386 (2016).

321 13. Riahi, K. et al. RCP 8.5-A scenario of comparatively high greenhouse gas emissions. 322 Clim. Change 109, 33-57 (2011).

323 14. Doney, S. C., Fabry, V. J., Feely, R. A. \& Kleypas, J. A. Ocean Acidification: The Other 324 CO2 Problem. Annu. Rev. Mar. Sci. 1, 169-192 (2009).

325 15. Kroeker, K. J., Kordas, R. L., Crim, R. N. \& Singh, G. G. Meta-analysis reveals negative 326 yet variable effects of ocean acidification on marine organisms. Ecol. Lett. 13, 1419-1434 327 (2010).

328 16. Mangan, S., Urbina, M. A., Findlay, H. S., Wilson, R. W. \& Lewis, C. Fluctuating 329 seawater $\mathrm{pH} / \mathrm{pCO} 2$ regimes are more energetically expensive than static $\mathrm{pH} / \mathrm{pCO} 2$ levels in 330 the mussel Mytilus edulis. Proc R Soc B 284, 20171642 (2017).

331 17. Pörtner, H.-O. Ecosystem effects of ocean acidification in times of ocean warming: a 332 physiologists view. Mar. Ecol. Prog. Ser. 373, 203-217 (2008).

333 18. Munday, P. L. et al. Ocean acidification impairs olfactory discrimination and homing 334 ability of a marine fish. Proc. Natl. Acad. Sci. 106, 1848-1852 (2009).

335 19. Watson, S.-A., Fields, J. B. \& Munday, P. L. Ocean acidification alters predator 336 behaviour and reduces predation rate. Biol. Lett. 13, 20160797 (2017).

337 20. Gruber, N. et al. Rapid Progression of Ocean Acidification in the California Current 
339 21. Kwiatkowski, L. et al. Emergent constraints on projections of declining primary

340 production in the tropical oceans. Nat. Clim. Change 7, 355-358 (2017).

341 22. Ishii, M. et al. Air-sea CO2 flux in the Pacific Ocean for the period 1990-2009.

342 Biogeosciences 11, 709-734 (2014).

343 23. Schuster, U. et al. An assessment of the Atlantic and Arctic sea-air CO2 fluxes, 1990344 2009. Biogeosciences 10, 607-627 (2013).

345 24. Sarma, V. V. S. S. et al. Sea-air CO2 fluxes in the Indian Ocean between 1990 and 346 2009. Biogeosciences 10, 7035-7052 (2013).

347 25. Lenton, A. et al. Sea-air $\mathrm{CO}_{2}$ fluxes in the Southern Ocean for the period

348 1990\&ndash;2009. Biogeosciences 10, 4037-4054 (2013).

349 26. Mongwe, N. P., Chang, N. \& Monteiro, P. M. S. The seasonal cycle as a mode to 350 diagnose biases in modelled CO2 fluxes in the Southern Ocean. Ocean Model. 106, 90-103 351 (2016).

352 27. Taylor, K. E., Stouffer, R. J. \& Meehl, G. A. An Overview of CMIP5 and the Experiment 353 Design. Bull. Am. Meteorol. Soc. 93, 485-498 (2011).

354 28. Rodgers, K. B. et al. A wintertime uptake window for anthropogenic $\mathrm{CO} 2$ in the North 355 Pacific. Glob. Biogeochem. Cycles 22, GB2020 (2008).

356 29. Egleston, E. S., Sabine, C. L. \& Morel, F. M. M. Revelle revisited: Buffer factors that 357 quantify the response of ocean chemistry to changes in DIC and alkalinity. Glob.

358 Biogeochem. Cycles 24, GB1002 (2010).

359 30. Hauck, J. \& Völker, C. Rising atmospheric CO2 leads to large impact of biology on 360 Southern Ocean CO2 uptake via changes of the Revelle factor. Geophys. Res. Lett. 42, 3612015 GL063070 (2015).

362 31. Orr, J. C. Recent and future changes in ocean carbonate chemistry. in Ocean 363 acidification 1, 41-66 (2011).

364 32. Kerrison, P., Hall-Spencer, J. M., Suggett, D. J., Hepburn, L. J. \& Steinke, M. Assessment of $\mathrm{pH}$ variability at a coastal $\mathrm{CO} 2$ vent for ocean acidification studies. Estuar. Coast. Shelf Sci. 94, 129-137 (2011). 33. Schulz, K. G. \& Riebesell, U. Diurnal changes in seawater carbonate chemistry speciation at increasing atmospheric carbon dioxide. Mar. Biol. 160, 1889-1899 (2013). 34. Jury, C. P., Thomas, F. I. M., Atkinson, M. J. \& Toonen, R. J. Buffer Capacity, Ecosystem 


\section{Acknowledgements}

This study was funded by the H2020 CRESCENDO grant (ref 641816) and the ERC IMBALANCE-P synergy grant (ref 610028). We acknowledge the World Climate Research Programme's Working Group on Coupled Modelling, which is responsible for CMIP. For CMIP the US Department of Energy's Program for Climate Model Diagnosis and Intercomparison provided coordinating support and led the development of software infrastructure in partnership with the Global Organisation for Earth System Science Portals. To analyse the CMIP5 data, this study benefited from the IPSL Prodiguer-Ciclad facility, which is supported by CNRS, UPMC, Labex L-IPSL which is funded by the ANR (ref ANR-10-LABX-0018) and by the European FP7 IS-ENES2 project (ref 312979). We thank B. Le Vu for preliminary discussions.

\section{Author contributions}

Both authors conceived this study, J.O. produced the derived variables, and both authors performed the analysis and wrote the manuscript, with L.K. leading the process.

\section{Additional information}

Correspondence and requests for materials should be addressed to L.K.

\section{Competing financial interests}

The authors declare no competing financial interests 


\section{Earth System Models}

Monthly surface-ocean carbonate chemistry fields were computed from monthly output of 9 CMIP5 models (Table S1) from prognostic fields for total alkalinity, dissolved inorganic carbon, temperature, salinity, and total dissolved inorganic phosphorus and silicon. Calculations were made offline using the mocsy package and the equilibrium constants recommended for best practices ${ }^{35}$. Output fields were regridded to a regular $1^{\circ} \times 1^{\circ}$ regular grid to facilitate multi-model intercomparison. All quoted error bars represent one standard deviation of the multi-model mean.

\section{Model evaluation}

CMIP5 seasonal climatologies constructed from 1995-2004 model output years were compared against the Takahashi et al., 2014 (ref. ${ }^{6}$ ) observational climatologies of $\left[\mathrm{H}^{+}\right], \mathrm{pH}$, $p \mathrm{CO}_{2}$ and $\Omega_{\text {arag }}$ (Supplementary Figs. 1-6). Model output was regridded to the Takahashi $4^{\circ} \mathrm{x}$ $5^{\circ}$ grid with the same ocean mask applied. The models generally capture the zonal-mean patterns of seasonality for observed climatologies of $\left[\mathrm{H}^{+}\right], \mathrm{pH}, p \mathrm{CO}_{2}$ and $\Omega_{\text {arag. }}$. The multi-model ensemble encompasses the observed seasonal variance for $\Omega_{\text {arag }}$ yet overestimates the seasonal variance of $\left[\mathrm{H}^{+}\right]$and $p \mathrm{CO}_{2}$ (Supplementary Figs. 1-2). This overestimation is driven by the zonal-mean component of seasonal variance (Supplementary Figs. 1-2). Across all carbonate chemistry variables, models have high correlation coefficients for the zonal-mean component of seasonal variability and relatively low correlation coefficients for the zonal-anomaly component of seasonal variability. Model performance is generally best in the subtropics and worst in the Southern Ocean with respect to both $\left[\mathrm{H}^{+}\right]$ and $\Omega_{\text {arag }}$ (Supplementary Figs. 3-6). Yet in the Southern Ocean, the data used to construct the climatologies are typically summer biased.

\section{Idealised simulations}

Three out of the 9 models also ran idealised simulations that allowed us to separate the geochemical effect from the $\mathrm{CO}_{2}$ increase from the radiative forcing effect of the same $\mathrm{CO}_{2}$ increase. More precisely, we used results from three CMIP5 experiments: 1pctCO2, esmFixClim 1 and esmFdbk1. Although these simulations are not directly comparable to those with the RCP8.5 scenario due to different simulation lengths and atmospheric $\mathrm{CO}_{2}$ concentrations, they provide the only means of separating the ultimate geochemical and radiative drivers of seasonality change. In the 1 pctCO2 simulations, the atmospheric $\mathrm{CO}_{2}$ concentration increases from $280 \mathrm{ppm}$ by $1 \%$ per year reaching a doubling $\left(2 \times \mathrm{CO}_{2}\right)$ after 70 years $(560 \mathrm{ppm})$ and quadrupling $\left(4 \times \mathrm{CO}_{2}\right)$ after 140 years. In the esmFixClim1 simulations, the atmospheric $\mathrm{CO}_{2}$ concentration follows that of the 1 pctCO2 simulations while the radiative module of each model experiences a constant atmospheric $\mathrm{CO}_{2}$ concentration of $280 \mathrm{ppm}$. Conversely, in the esmFdbk1 simulations, the atmospheric $\mathrm{CO}_{2}$ concentration is held constant at $280 \mathrm{ppm}$ but the radiative module of each model experiences the same $\mathrm{CO}_{2}$ concentration as the $1 \mathrm{pctCO} 2$ simulations. The mean response of the models in the 1pctCO2 simulations is similar spatially to that of the multi-model ensemble in RCP8.5 simulations (Figs. 3, 4). This confirms that atmospheric $\mathrm{CO}_{2}$ emissions are the driver of patterns of 
carbonate chemistry seasonality change and validates the use of the esmFixClim1 and esmFdbk1 simulations to partition the radiative and geochemical influences of $\mathrm{CO}_{2}$. It should be noted that there are limited increases in ocean temperatures in the esmFixClim 1 simulations that result from changes associated with the terrestrial biosphere, for which elevated $\mathrm{CO}_{2}$ reduces stomatal conductance, which in turn drives greater surface sensible heat fluxes and thus slight increases in temperatures ${ }^{36}$.

\section{Taylor-series deconvolution}

487

The first-order Taylor-series deconvolution was performed for $\left[\mathrm{H}^{+}\right]$and $\Omega_{\text {arag }}$ independently with output from the RCP8.5 simulations (eqn. 2). The partial differential terms were estimated numerically using the mocsy package and $\Delta \mathrm{T}, \Delta C_{\mathrm{T}}, \Delta A_{\mathrm{T}}$ and $\Delta \mathrm{S}$ represent the change in input variables synchronous with $\Delta y$. This approach reproduces the changes in the seasonal amplitude of each of the derived variables $\left[\mathrm{H}^{+}\right]$and $\Omega_{\text {arag }}$ to within much less than 1 $\%$ as shown in Figure S9. With the exception of the very high latitudes, the deconvolution was broadly consistent across the multi-model ensemble. The zonal-mean influence of the different terms is given in the supplementary material for the representative GFDL-ESM2M model (Supplementary Figs. 9-11).

\section{Data availability}

All the CMIP5 ESM model data are available via the Earth System Grid Federation (ESGF). The derived data that support the findings of this study are available from the corresponding author upon request.

\section{References}

35. Dickson, A. G., Sabine, C. L. \& Christian, J. R. Guide to Best Practices for Ocean CO2 Measurements. (North Pacific Marine Science Organization, 2007).

\section{Sellers, P. J. et al. Comparison of Radiative and Physiological Effects of Doubled} Atmospheric CO2 on Climate. Science 271, 1402-1406 (1996). 